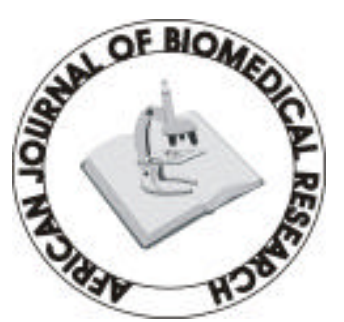

Full-text available at http://www.ajbrui.com \&

http://www.bioline.br/md

Received:

January 2006

Accepted:

March 2006

Published

May 2006
Short communication

\section{A Rwandan spirometry and resting ventilation study}

\author{
Jean Bosco Gahutu* ${ }^{*}$ and Justin Wane ${ }^{* *}$
}

*Service of Normal and Pathologic Physiology, Faculty of Medicine, National University of Rwanda; P.O. Box 30 Butare, Rwanda

** Association of African Universities; P.O. Box AN 5744 Accra North, GHANA

\section{ABSTRACT}

To illustrate spirometric population variation and ventilatory adaptation to moderate altitude, we report the spirometric and resting ventilation values observed in a student population in Butare, Rwanda (altitude: 1 $768 \mathrm{~m}$; barometric pressure: $629 \mathrm{~mm} \mathrm{Hg}$ ). Spirometry was carried out with a Mijnhardt Volutest VT-3 water-sealed spirometer in students aged between 20 and 30 years. The results (mean $\pm S D$ ) are as follows: Vital capacity: males: $4123 \pm 537 \mathrm{~mL}$, females: $2810 \pm 393 \mathrm{~mL}$; Vital capacity per $m^{2}$ body surface area: males: $2352 \pm 245 \mathrm{~mL} / \mathrm{m}^{2}$, females: $1771 \pm$ $219 \mathrm{~mL} / \mathrm{m}^{2}$; FEV1: males: $3576 \pm 618 \mathrm{~mL}$, females: $2347474 \mathrm{~mL}$; FEV1\%: males: $87.8 \pm 8.5 \%$, females: $84.5 \pm 7.7 \%$; tidal volume: males: $540 \pm 80 \mathrm{~mL}$, females: $454 \pm 66 \mathrm{~mL}$; respiratory frequency: $17 \pm 4$ both in males and in females; minute volume: males: $9.3 \pm 2.7 \mathrm{~L} / \mathrm{min}$., females: $7.6 \pm 2.0 \mathrm{~L} / \mathrm{min}$. The results indicate that the vital capacity and the FEV1 are lower than classical values from white populations, FEV1\% is higher. The tidal volume, respiratory frequency and minute volume are increased relative to sea level. (Afr. J. Biomed. Res. 9: 137 - 140, May 2006)

Keywords : FEV1, Vital Capacity, high altitude, ventilation

${ }^{\S}$ To whom correspondence should be addressed:

Tel.: +250 530475; Fax: +250 530328; E-mail address:.jgahutu@nur.ac.rw 


\section{INTRODUCTION}

Spirometry is important in pulmonary diagnosis; it is often carried out in practice to check the pulmonary function (Crapo, 1994). Spirometric results depend on several influencing factors, notably age, height, weight, body surface area, sex and race (White et al., 1994). Significant deviation from normal values can be used as an aid to pulmonary diagnosis. High altitude increases pulmonary ventilation by acclimatization to high altitude hypoxemia (Lenfant and Sullivan, 1971; Schoene, 1997); however there are population differences (Frisancho et al., 1999; Moore, 2000). Its effects on lung volumes are negligible at altitudes lower than $1800 \mathrm{~m}$ (Brändli et al., 1996; Fiori et al., 2000; Gaultier and Crapo, 1997). We recently described blood gas, acid-base and hemoglobin characteristics in Butare, Rwanda (altitude: $1768 \mathrm{~m}$, barometric pressure: $629 \mathrm{~mm} \mathrm{Hg}$ ); acclimatization to moderate altitude was observed, characterized by a slight chronic respiratory alkalosis with complete metabolic compensation (Gahutu et al., 2005).

We report here spirometric values observed in Rwandan university students in Butare, so far the only spirometry study carried out in the Rwandan population.

\section{SUBJECTS AND METHODS}

Spirometric measurements were carried out on voluntary non-smoker students of the National University of Rwanda, aged between 20 and 30 years, in apparent good health, without any respiratory disease. Sex and age were recorded for each subject. The weight and height were measured on slightly clothed subjects without shoes. We did not measure the sitting height. We used a Mijnhardt Volutest VT -3 water-sealed spirometer in compliance with the manufacturer's instructions (Mijnhardt, Odijk, Holland). The spirometer has a $9 \mathrm{~L}$ bell; its normal speed is $60 \mathrm{~mm} / \mathrm{min}$ and its speed during FEV1 maneuver is $1200 \mathrm{~mm} / \mathrm{min}$. The spirometer system was leak-proof. Soda lime was used for trapping $\mathrm{CO}_{2}$ and the spirogram curve was stabilized by an oxygen supply. The smallest unit of the spirogram paper was $50 \mathrm{~mL}$, permitting an acceptable accuracy (Quanjer $e t$ al., 1993). The test subjects were in resting conditions, 2-5 hours after the meal, in sitting position and with a nose clip. Ambient temperature was around $24^{\circ} \mathrm{C}$. One maneuver of relaxed vital capacity was performed: after a maximum inspiration, the test subject expired as deeply as possible, and the vital capacity value was determined by measuring the maximum amplitude of the recorded spirogram. One maneuver of forced vital capacity was also performed: after a maximum inspiration, the test subject expired as fast and as deeply as possible; forced vital capacity was determined by measuring the maximum volume forcefully expired. In case of difference between relaxed vital capacity and forced vital capacity, the highest value was retained as vital capacity. The maneuver of forced vital capacity also permitted to determine the FEV1 (forced expiratory volume in 1 second: volume forcefully expired in the first second) and the FEV $1 \%$ (forced expiratory volume in 1 second in $\%$ of the forced vital capacity). Volumes were transformed from ATPS (ambient temperature and pressure, saturated with water vapor) to BTPS (body temperature and pressure, saturated with water vapor) with an appropriate formula (Quanjer et al., 1993). The body surface area was calculated according to the formula of DuBois in order to calculate the vital capacity per $\mathrm{m}^{2}$ of body surface area.

\section{Statistical Analysis}

The results were analyzed on the computer with EpiInfo 6.04 software.

\section{RESULTS}

The mean age of the subjects was 24 years for males and 23 years for females. The anthropometric data of test subjects (mean \pm SD) are as follows: Weight: 64.2 $\pm 6.5 \mathrm{~kg}$ in males and $57.8 \pm 8.7 \mathrm{~kg}$ in females. Height: $172.4 \pm 6.7 \mathrm{~cm}$ in males and $160.2 \pm 6.0 \mathrm{~cm}$ in females. Body surface area: $1.76 \pm 0.11 \mathrm{~m}^{2}$ in males and $1.59 \pm 0.11 \mathrm{~m}^{2}$ in females.

The spirometric and resting ventilation results (mean $\pm \mathrm{SD}$ ) are shown in Fig. 11 .

\section{DISCUSSIONS}

Compared with classical theoretical values obtained from European and American populations, vital capacity is lower in our study, both in males and in females, due to a lower inspiratory reserve volume; the expiratory reserve volume is higher. 

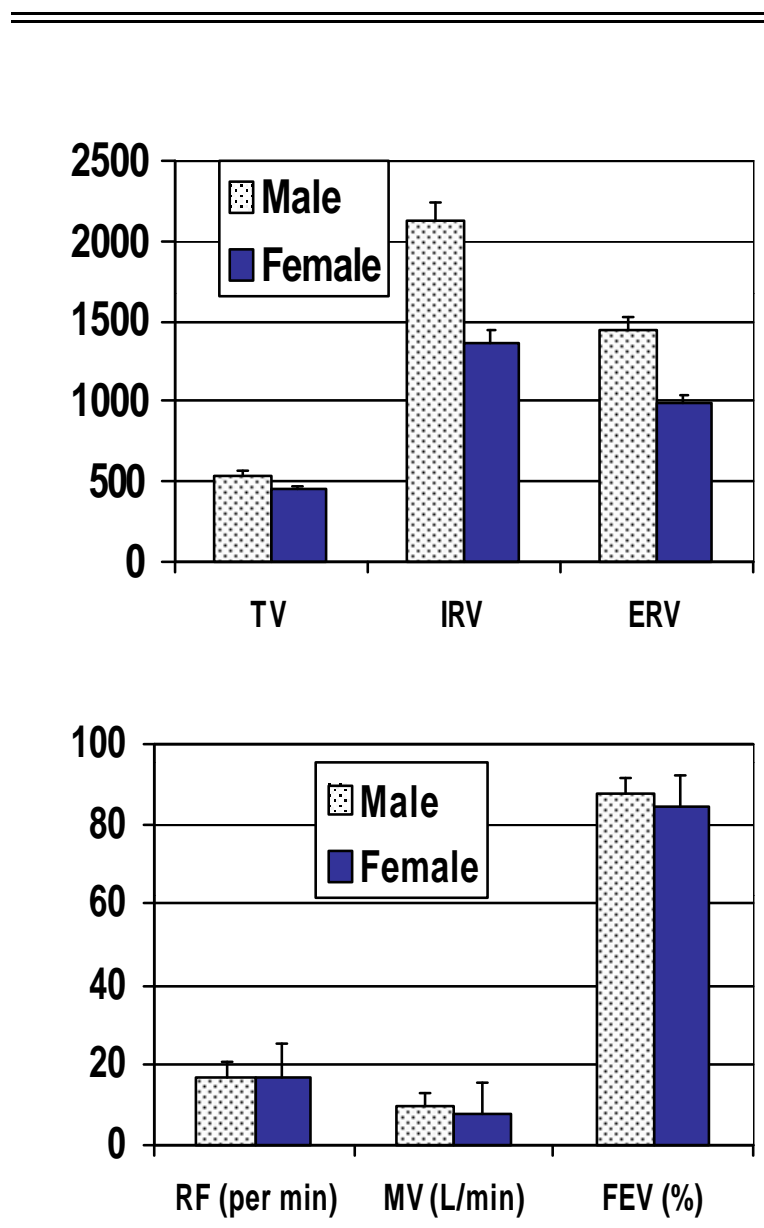

Variations in vital capacity values in African, American, Asian and European populations are classical (Goldin et al., 1996; Louw et al., 1996; Quanjer et al., 1993). Lower values of vital capacity in African populations have been reported in males and females (Dufetel et al., 1989; Goldin et al., 1996; Louw et al., 1996; Mengesha and Mekonnem, 1985; Mustafa, 1977; Quanjer et al., 1993). This is also the finding of our study, in which the decrease in vital capacity is $14 \%$ in males and $12 \%$ in females while the decrease of the vital capacity per $\mathrm{m}^{2}$ of body surface area is $9 \%$ in males and $15 \%$ in females. Differences in the above mentioned studies are similar. Besides anthropometric differences (Goldin et al., 1996; Hankinson et al., 1999; Quanjer et al., 1993), nutritional and socio-environmental factors may play a role in the lower FVC observed in Africans (Gaultier and Crapo, 1997; Goldin et al., 1996; Quanjer et al., 1993). Lower values observed in our series are not due to the sitting position, since in young adults it does not lower the vital capacity relative to the standing position (Quanjer et al., 1993).

The $\mathrm{FEV}_{1}$ is also lower than classical values in our series (10\% in males and $8 \%$ in females); lower FEV1 values in Africans have also been found by other authors (Dufetel et al., 1989; Hankinson et al., 1999; Mengesha and Mekonnem, 1985; Mustafa, 1977). The FEV1\% in our series is $5 \%$ higher than the classical mean value, both in males and in females, probably due to a lower vital capacity. In other studies, the ratio is similar in black and white subjects (Dufetel et al., 1989; Hankinson et al., 1999).

The tidal volume, the respiratory frequency and the minute volume are higher than at sea level both in males and in females. This is due to acclimatization to altitude that we illustrated in a recent study, showing in Butare a $\mathrm{P}_{\mathrm{a}} \mathrm{O}_{2}$ of 83.0 and $84.5 \mathrm{~mm} \mathrm{Hg}$, a $\mathrm{PaCO}_{2}$ of 34.7 and $31.8 \mathrm{~mm} \mathrm{Hg}$ and a hemoglobin oxygen saturation of 97.0 and $94.7 \%$ in males and females respectively (Gahutu et al., 2005). This

Fig. 1: increase in minute volume is a classical altitude respiratory adaptation (Frisancho et al., 1999; Lenfant and Sullivan, 1971; Schoene, 1997). The observed minute volume in males and in females is about $55 \%$ higher than at sea level, indicating a slight hyperventilation. This is mainly attributable to altitude acclimatization. However, the subjects were not in basal conditions (not fasting since at least 12 hours). Spirometry was done 2-5 hours after the meal and the resting metabolism determined by indirect calorimetry using the same spirometer showed a mean increase of 
$14 \%$ in the males and $7 \%$ in the females relative to the predicted theoretical basal metabolic rate for the test subjects. Therefore, part of the increase in ventilation was due to resting metabolism. At a slightly lower altitude of $1680 \mathrm{~m}$, a comparable ventilation was observed in males: $153 \pm 5.7 \mathrm{~mL} \cdot \mathrm{min}^{-1} \cdot \mathrm{kg}^{-1}$; weight: $64.3 \pm 1.5 \mathrm{~kg}$ (mean $\pm \mathrm{SD}$ ) (Serebrovskaya and Ivashkevich, 1992). At higher altitudes, the increase in ventilation is greater (Frisancho et al., 1999; Schoene, 1997; Serebrovskaya and Ivashkevich, 1992).

The difference observed between males and females, with pulmonary volumes and capacities 20 to 25 percent lower in females than in males is classical (Quanjer et al., 1993).

\section{ACKNOWLEDGEMENTS}

We are very grateful to the test subjects for their cooperation.

\section{REFERENCES}

Brändli O, Schindler C, Künzli N, Keller R, Perruchoud AP, SAPALDIA team (1996): Lung function in healthy never smoking adults: reference values and lower limits of normal of a Swiss population. Thorax 51, 277-283.

Crapo RO (1994): Pulmonary-function testing. $N$ Engl $J$ Med 331, 25-30.

Dufetel P, Pigearias B, Lonsdorfer J, Derossi G, Diaine C, Faltot PJ (1989): Spirometric reference values in Senegalese black adults. Eur Respir J2(4), 352-358.

Fiori G, Facchini F, Ismagulov $O$, Ismagulova A, Tarazona-Santos E, Pettener D (2000): Lung volume, chest size, and hematological variation in low-, medium, and high-altitude central Asian populations. Am J Phys Anthropol 113(1), 47-59.

Frisancho AR, Juliao PC, Barcelona V, Kudyba CE, Amayo G, Davenport G, Knowles A, Sanchez D, Villena M, Vargas E, Soria R. (1999): Developmental components of resting ventilation among high- and low-altitude
Andean children and adults. Am J Phys Anthropol 109(3), 295-301.

Gahutu JB, Wane J, Uwambazimana JA, Midonzi D, Twagirumugabe T, Ndoli MJ, Leybaert L (2005): A Rwandan altitude blood gas, acid-base and hemoglobin study. Clin Chim Acta 357(1), 86-87.

Gaultier C, Crapo R (1997): Effects of nutrition, growth hormone disturbances, training, altitude and sleep on lung volumes. Eur Respir J 10, 2913-2919.

Goldin JG, Louw SJ, Joubert G (1996) Spirometry of healthy adult South African men. Part II. Interrelationship between socio-environmental factors and 'race' as determinants of spirometry. S Afr Med J86(7), 820-826.

Hankinson JL, Odencrantz JR, Fedan KB (1999): Spirometric reference values from a sample of the general U.S. population. Am J Respir Crit Care Med 159, 179-187.

Lenfant C, Sullivan K (1971): Adaptation to high altitude. N Engl J Med 284(23), 1298-1309.

Louw SJ, Goldin JG, Joubert G (1996): Spirometry of healthy adult South African men. Part I. Normative values. S Afr Med J 86(7), 814-819.

Mengesha YA, Mekonnem Y (1985): Spirometric lung function tests in normal non-smoking Ethiopian men and women. Thorax 40(6), 465-468.

Moore LG (2000): Comparative human ventilatory adaptation to high altitude. Respir Physiol 121, 257-276.

Mustafa KY (1977): Spirometric lung function tests in normal men and African ethnic origin. Am Rev Respir Dis 116(2), 209-213.

Quanjer PH, Tammeling GJ, Cotes JE, Pedersen OF, Peslin R, Yernault, J-C (1993): Lung volumes and forced ventilatory flows. Eur Respir J6(Suppl.16), 5-40.

Schoene RB (1997): Control of breathing at high altitude. Respiration 64, 407-415.

Serebrovskaya TV, Ivashkevich AA (1992): Effects of a 1yr stay at altitude on ventilation, metabolism, and work capacity. J Appl Physiol 73(5), 1749-1755.

White NW, Hanley JH, Lalloo UG, Becklake MR (1994): Review and analysis of variation between spirometric values reported in 29 studies of healthy African adults. $A m$ $J$ Respir Crit Care Med 150(2), 348-355 